\title{
On the Application of Multimedia Teaching Method in the Teaching of Chinese National Folk Dance
}

\author{
Rui Wang \\ College of the Arts, Guangxi University, Nanning, 530004, China
}

Keywords: Multimedia teaching method; Chinese national fold dance; Application in teaching

\begin{abstract}
With the development of modern science and technology, multimedia is used extensively in teaching, the transformation of teaching media changes teaching mode, and the teaching of national folk dance of our country meets unprecedented challenge and opportunity. The development of multimedia technology and the popularity of its application in teaching weaken the role of teacher and highlight the teaching advantage. This article, through the analysis of the feasibility and media of the application of multimedia teaching method in the teaching of Chinese national folk dance, discusses the features of the application of multimedia teaching method in Chinese national folk dance.
\end{abstract}

\section{Preface}

Function of multimedia system resembles personal computer, which has significance on development of human society. From the current society, multimedia technology not only affects people's traditional life style, but also has positive influence on all walks of society. Education field, as one of them, has experienced dramatic changes along with the development of internet and science and information technology. Some parts of education such like teaching mode, curriculum and communication between teachers and students become the emphases of the application of multimedia teaching method.

\section{Feasibility of the Application of Multimedia Teaching Method in the Teaching of Chinese National Folk Dance}

\section{Necessity}

With the constant development of science and technology in our country, educational objective becomes continuously improved and perfect, and teaching method has changed greatly. Science and modernization have become two flags of modern education; teaching of national folk dance follows the trend of the age: with the changes of classroom environment, teaching content and training methods increase the teaching efficiency dramatically. The development of the age does not allow teaching of national folk dance to stay inflexible on the traditional teaching stage. Needs for diversified and artistic knowledge make the teaching of national folk dance gradually get rid of the original shackles, because of which teaching emphases and content are developed in a large scale. Multimedia technology becomes a key point of these achievements.

\section{Effectiveness}

Multimedia technology can enhance students' initiative in classroom and stimulate their interest for the promotion of national innovation, while the traditional single mode of teaching would gradually fade away. The advantages of multimedia teaching are obvious, which can make teaching in classroom more intuitive and easy to understand. Contrast and interactive teaching method also increases students' emotional consciousness of dance culture and cultivate their comprehensive quality, which triggers diversified teaching mode of national folk dance. Defects such as "only words in classroom" and "learning movements" of traditional teaching can be improved, and the culture of our national folk dance begins to flow into students' hearts. Multimedia teaching creates a good 
atmosphere for dance, where sense of situation is richer and students can accurately grasp the dance movements, dance expression and dance positioning. Teachers and students can make progress in a pleasant communication, meanwhile students' initiative and enthusiasm can be enhance, which are the key points deciding the efficiency of the whole class.

\section{Rationality}

Substantial explicitness and psychological implicitness are two main expression ways of classroom movements in dance teaching. Physical explicit space is what we can see such as bird, tree, flower and grass. The motion of these external things can be expressed through the dancer's performance, which is a movement of thinking, a thing that can be sensed by students and be measured based on students' observation. While psychological invisible space is an inherent emotional perception, out of the control of body bones or ligament, which conveys the concept of rhythm. It is the crystalline of human emotion and spirit, for example, couple dance moves convey a kind of harmony and an interdependence warm picture. Language logic of dance is the most prominent feature, with a characteristic that outsiders couldn't perceive and it can connect to external things to dominate the actions. Because of space limitations, dance thinking without logic is the block which is hard for teachers to overcome. Teaching of national folk dance must meet the specifications and the styles, while the control of style needs the dancer to have inherent emotional sedimentation and understanding of the dance background. This defect in performance of style from psychological implicitness can be made up by multimedia technology. The vivid teaching method inspires students' imagination, which can improve the performance of national folk dance of students fundamentally, and ultimately achieves a multiplier effect.

\section{Media for the Application of Multimedia Teaching Method in the Teaching of Chinese National Folk Dance}

Nowadays, the development of the media for multimedia teaching is diversified; all media such as images and sound work complementary in a joint action and ultimately achieve the ideal efficiency of classroom teaching based on diversified teaching methods.

\section{Image media}

The main application of image reflects on the media player of PPT and picture. In teaching of national folk dance, image media plays an important role for students to understand the local customs and terrain topography, while this kind of information was boring in traditional teaching method. Living conditions of local people, costumes and facial features are displayed by PPT, which can provide students with inspirations of physical movements, and students can make a secondary creation in the integration of local culture in an imaginable space. Besides, the image processing software, as a special recording mode, successfully turns static images into dynamic images, getting rid of the constraint of time and space; screenshots help students to examine their learning outcomes at different stages, achieving the combination of visual and aural effect.

\footnotetext{
Audio media

In the piano accompaniment of our national fold dance, the unique timbre of western musical instrument decides its defects when expressing different accompaniment music, while multimedia teaching can make up this deficiency in a large part. Different melody rhythm of dance music makes students have different psychological emotion, which is helpful to convey the local folk culture and to avoid the flexible but single and barren situation of traditional musical accompaniment. Multimedia technology allows the prerecorded music to be the accompaniment music, which offers a convenient to teaching of Chinese folk dance and strengthens the randomness of space and time, making the tape recorder and tape become history.
} 


\section{Features of the Application of Multimedia Teaching Method in the Teaching of Chinese National Folk Dance}

To convey self emotion through physical movement is the main feature of our national folk dance, dance of Tibetan, Mongolian and Chaoxian Nationality are important components. Because of their brisk rhythm, rich content and elegant style, they are widely used by teachers. The flexibility and diversity of our national folk dance add difficulty for teachers to organize teaching. How to make students better remember the dance moves, enhance the emotion of music and show the unique culture of our nation by focusing on teamwork is a major issue of professional practitioners.

\section{Optimization of Teaching Resources to Enrich Dance Teaching}

Application of multimedia teaching method in the teaching of Chinese national folk dance improves the standard of teaching dramatically. Courseware in multimedia technology enriches teachers' teaching resources; innovative teaching methods improve the overall level of teachers and students. Multimedia teaching can display the dance moves all around to students, illustrating to explain the queue or orientation arrangement. Multimedia teaching method can further refine the difficult points in dance to achieve flexible control. The application of multimedia image takes on obvious comparison of different cultures of different folk dance, so that students' physical movements would have more accurate emotional language and morphological composition.

\section{Optimization of Teaching Environment to Enhance Students' Understanding of Style of Chinese National Folk Dance}

It is a wonderful thing for students, through contacting of surrounding environment and beautiful things at the best age, to enrich their temperament and interest and emotional experience. Multimedia technology turns the traditional black classroom into colorful environment; vivid images and unique aural efficiency create a good teaching atmosphere. Students can enhance their understanding of the features of local nationalities through self emotion and cognition, understanding the attractive auxiliary factors behind dance. Dance move of Mongolian dance is strong and bold, Chaoxian nationality's dance is elegant, Uygur ethnic group's dance is cheerful and lively; all these features spur students' learning desire, which improve the teaching efficiency. For example, during the teaching of "Golden Peacock", the cultural features of Dai nationality are strange to most students. It would be hard for students to understand the local culture only by explaining of pictures; but the emergence of multimedia technology creates a teaching environment with video or record. Through the students' observation of peacock, students can show better the beauty of physical body.

\section{Warming up Students' Sense Organs to Make up the Limitations of Teacher's Individual Performance}

According to the statistics of related documents, in the process of getting external information, information gotten by vision sense takes up 83\%, auditory sense occupies $11 \%$, and taste sense $11 \%$, information grasped by tactile sense and olfactory sense are both $5 \%$. So, when people get external information, vision sense and auditory sense do most of the work. The application of multimedia technology in national folk dance teaching in our country makes visual and aural teaching become possible. Under the influences of high-tech, students' sense organs are simulated, with strong intensity of receiving information. It avoids traditional barren repeated teaching of dance moves. Application of video, record and other media makes teaching attractive with image and music. Students can achieve educational objective faster by playback and teacher's instruction of dance moves, which can strengthen students' initiative of learning dance and help teacher to get rid of the dull, dry and repeated moves. And sense organs absorbing information together is helpful to turn dance culture into self-cultivation. 


\section{Broadening Students' Horizons to Stimulate the Interest to Learn Chinese National Folk Dance and Second Creative Power}

Students' potential to create is great and they have strong curiosity toward external things. After they have mastered the style and rhythm of national folk dance to some extent, they would have strong desire of self-creation. Teachers can encourage students to rearrange the dance without changing the original dancing rhythm. For example, in the teaching process of Mongolian folk dance, students can learn by watching good dancing films after they have mastered basic dance moves; on the base of deep understanding of local national culture and local customs and practices, they can know how to rearrange the rhythm and move types of dance, making the performance of physical body more emotional.

\section{Providing Platform of Cyber Resource for Teachers to Restudy}

The main contents of the teaching of national folk dance in our country are to be familiar with minority nationalities, to experience their lives, to learn moves of folk dance and create dance. In the process of applying multimedia in preparing lessons, teachers can look it as a process of restudy when they choose pictures, music and costumes from internet. According to students' characteristics, teachers choose the most suitable contents to prepare for class, and organize the teaching process and adjust the arrangement of teaching in accordance with students' actual learning conditions. The application of multimedia teaching in the teaching of national folk dance not only makes educational objective clear, but also encourages teachers to have understandings of folk dance culture advancing with the times and work out more scientific teaching mode in classroom.

\section{Creating Dance Notation Teaching Mode to Help Students to Distinguish Difficult Points in Teaching}

To help students to better memory the contents which our national folk dance tries to express, teachers can use the advantages of multimedia technology to create dance notation teaching mode, just as the teaching of percussion music, letting students make clear of the difficult points in teaching. Teachers' focuses move from demonstration of dance moves to how to make the images be understood by students directly. Traditional images gradually fade into wilderness, replacing by fresh and lovely stories and dynamic linear graph. For example, in the teaching of "Grape Harvest", the application of CAJ courseware offers clear team choreography. It also provides convenience for classroom teaching by input students' head pictures which move according to the changes of team choreography. Student's sense organs are stimulated at the same time and they can have a faster and more thorough understanding of teaching content.

\section{Constructing New Channels for Learning and Exchange to Realize Synchronization of Family Teaching in National Folk Teaching}

Parents' meeting, family contact information and family visits are the important traditional channels for colleges to communicate with parents, but with the diversification of communication ways such as QQ group, Weibo, blog and Weixin, communication between teachers and parents becomes more convenient with the development of internet, by this way learning conditions of students can be understood and assisted by parents. For example, in QQ group of class, teaching progress and learning outcomes can be passed to parents in time by group announcements and group space, so is a series of the latest notification; high quality education resources of dance can be shared and counseling online can be achieved.

\section{Conclusion}

In summary, the development of teaching of national folk dance needs the full application of multimedia technology. Multi values produced in classroom of intense atmosphere will bring a new side to the teaching of Chinese folk dance. As we all know, teaching by multimedia technology is a reproduced comprehensive transfer, an optimization process of recording. Fundamental improvement 
of teaching capacity, teaching time and teaching efficiency guarantees the quality of teaching and increases students' interest. With the constant development of national economy and science, multimedia technology teaching will definitely become one of the indispensable application technologies in the teaching of national folk dance. Although multimedia PPT, audio-visual technology and other assistive technologies have become routine things in dance teaching at major universities, there are still many flaws to be explored and improved. To make teaching of multimedia technology fully integrate into the teaching of national folk dance in our country, relevant practitioners need to make continuous efforts.

\section{References}

[1] Liu Dongxu. "Dance for the Age---On the Application of Modern Multimedia in Dance Teaching. Music Space. 2014(09):23-25

[2] Li Jianhua. Popularity of Higher Education---On the New Teaching Mode in Music Art Profession in Higher Education. Collection of Articles in Symposium of Development of National Higher Education of Music and Study of Teaching (2rd volume).2011

[3] Lv Yan. Study on the Application of Multimedia Technology in Dance Teaching. Science and Technology Innovation and Industry Development (B volume)-Articles Collection of 7th Shenyang Science Academic Annual Symposium and Hunnan High-tech Industry Development Forum.2010

[4] Li Rui, Zhu Jun. Positive Influences on Digital Multimedia Technology on Dancing Teaching. Art Education. 2011(08):21-25

[5] Fan Yanhua, Long Youcheng. Status of Dancing Teaching and Mode Construction of Preschool Education Major in Normal College. Journal of Jiamusi Education College.2011(08):22-56

[6] Sun Qiao. On the Application of Multimedia Technology in Dancing Teaching. Scientific Education Newspaper (Educational Research).2011(25):45-47

[7] Zhu Guanghai, Huang Xingshuai. Training Students' Innovation by Modern Educational Technology. Journal of Anhui Institute of Education. 2013(06):56-67 